\title{
Aspectos histológicos das lesões hepatotóxicas no exame post mortem de bovinos
}

\author{
Histological aspects of hepatotoxic lesions in the bovine \\ post mortem exam
}

Renata Falcão Rabello da Costa, ${ }^{*}$ Kelly Cristina Demarque, ${ }^{* *}$ lacir Francisco dos Santos, ${ }^{* * *}$ Hugo Verardino, ${ }^{* * * *}$
Leonel Augusto Martins Almeida, ${ }^{* * *}$ José Gabriel Amoril, ${ }^{* * *}$ Marcius Ribeiro de Freitas, ${ }^{* * * *}$ Rogério Tortelly***

\begin{abstract}
Resumo
A Brachiaria sp. tem sido incriminada em casos de intoxicação em ruminantes, acarretando quadros de fotossensibilização hepatógena, pela ingestão de saponinas esteroidais. O fígado pode apresentar tonalidade desde levemente esbranquiçada até amarelada. Microscopicamente, podem ser vistos macrófagos espumosos distribuídos pelo parênquima hepático e cristais opticamente ativos na luz dos ductos biliares. De um total de 220 amostras, foram observados 41 (18,63\%) casos de macrófagos espumosos em fígados de bovinos provenientes dos estados de São Paulo e Goiás. As principais características histológicas de tais células foram a disposição em ninhos, em grandes massas subcapsulares ou difusa no parênquima que determinou, inclusive, a formação de ilhotas de hepatócitos, fibrose e hiperplasia de ductos biliares. Notou-se, também, colangiohepatite granulomatosa, rica em células gigantes multinucleadas, centralizada por cristais birrefringentes. Em alguns casos o órgão apresentou aspecto leitoso ou características de esteatose, mas em sua maioria a coloração era normal. Tendo em vista o caráter tóxico da Brachiaria sp. sugere-se que o fiscal agropecuário aplique os dispositivos regulamentares cabíveis em qualquer caso de alteração de tonalidade do fígado e associe as manifestações clínicas de fotossensibilização com possíveis lesões hepáticas no exame post mortem.
\end{abstract}

Palavras-chave: macrófagos espumosos, Brachiaria sp., bovino, hepatotoxicose, inspeção sanitária.

\begin{abstract}
Hepatogenous photosensitization of ruminants has been associated with the ingestion of steroidal saponins of Brachiaria sp. The liver can show since slightly whitish to yellowish tonality. Microscopically, can be seen foam cells distributed in the hepatic parenchyma and birefringent crystalloid deposits in the biliary tract. Of 220 samples, forty one (18,63\%) cases of foam cells were observed in bovine liver from São Paulo and Goiás States. The main histological characteristics of such cells were their arrangement in nests, big masses in the subcapsular area or diffusing in the parenchyma which has determined hepatocytes nests, fibrosis and hyperplasic biliary ducts. Granulomatous cholangiohepatitis, full of multinucleated giant cells, centralized by birefringent cristalloid material was also observed. In some cases the liver was milky or fatty, but the majority was normal in color. Due to the toxicity of Brachiaria sp., the inspector should apply specific legal procedures in any cases oh hepatic colors alterations and associate the photosensitization signs with possible hepatic lesions in the post mortem exam.
\end{abstract}

Keywords: foam cells, Brachiaria sp, bovine, hepatotoxicity, sanitary inspection.

\section{Introdução}

A relação entre a fotossensibilização, a esporidesmina, micotoxina do Pithomyces chartarum, e a Brachiaria decumbens em lesões hepáticas de ruminantes foi descrita por vários pesquisadores (Döbereiner et al.,1976; Temperini e Barros, 1977; Fagliari et al., 1983; Fagliari et al., 1993; Alessi et al., 1994). Contudo, estudos de casos de fotossensi- bilização hepatógena em ovinos, caprinos e bovinos indicam que a moléstia possa ser causada por saponinas esteroidais da própria Brachiaria sp. (Smith e Miles, 1993; Miles, 1993; Lemos et al.,1996 a; Lemos et al., 1996 b; Meagher et al., 1996; Lemos et al., 1997 a; Lemos et al., 1997 b; Driemeier et al., 1997; Driemeier et al.,1998; Driemeier et al., 1999; Cruz et al., 1999; Cruz et al., 2000). As saponinas são glicosídeos que alteram a permeabilidade das paredes celulares, sendo

\footnotetext{
Programa de Pós-Graduação em Medicina Veterinária (Doutorado) - Higiene Veterinária e Processamento Tecnológico de Produtos de Origem Animal. Faculdade de Veterinária. Universidade Federal Fluminense - UFF. Niterói/RJ.

** Vigilância Sanitária Municipal de Piraí, RJ.

*** Departamento de Tecnologia dos Alimentos. Faculdade de Veterinária - UFF. Rua Vital Brazil Filho, n 64, Vital Brazil, Niterói/RJ, Brasil. CEP: 24230-340.

${ }^{* * * *}$ Fiscal Federal Agropecuário - M.A.P.A.

Autor para correspondência: Renata Falcão Rabello da Costa. E-mail: rrfalcosta@yahoo.com.br.
} 
tóxicas para todos os tecidos organizados (Blakiston, 1979). Além de estarem sendo identificadas na Brachiaria decumbens, em conteúdo ruminal (Noordin et al., 1989; Salam Abdullah et al., 1992; Lajis et al., 1993) e em bile (Cruz et al., 2000) de ovinos intoxicados por esta forrageira, a presença da esporidesmina não tem sido confirmada em muitos surtos no Brasil (Lemos et al.,1996 a; Lemos et al., 1996 b; Lemos et al., 1997 a; Lemos et al., 1997 b; Driemeier et al., 1997; Cruz et al., 1999).

O fígado de animais intoxicados pode exibir tonalidade desde levemente esbranquiçada (Cruz et al., 1999; Cruz et al., 2000) até amarelada (Lemos et al., 1997; Driemeier et al., 1998), com intensidades variáveis, aumento da consistência, do volume e do padrão lobular (Lemos et al., 1996 a).

A presença de cristais opticamente ativos é considerada a alteração histológica mais consistente nos casos de fotossensibilização hepatógena por ingestão de plantas que contêm as saponinas esteroidais, pois acredita-se que o material cristalóide depositado possa causar obstrução do fluxo biliar (Smith e Miles, 1993; Lemos et al., 1996 a; Meagher et al., 1996; Cruz et al., 1999; Cruz et al., 2000). A despeito desse achado microscópico, têm sido relatadas células multinucleadas, com núcleos excêntricos e citoplasma espumoso, distribuídas aleatoriamente, no parênquima hepático (Lemos et al., 1997 b; Driemeier et al., 1998; Driemeier et al., 1999), em linfonodos hepáticos (Lemos et al., 1996 a; Lemos et al., 1997b; Driemeier et al., 1998), em linfonodos mesentéricos (Driemeier et al., 1998; Cruz et al., 1999) e no baço (Driemeier et al., 1998; Driemeier et al., 1999). A observação dos macrófagos espumosos foi descrita, inclusive, em animais clinicamente sadios, alimentados com tal gramínea (Driemeier et al., 1998)

Objetivou-se neste estudo relatar a ocorrência de macrófagos espumosos em fígados de bovinos clinicamente sadios, oriundos de matadouros-frigoríficos sob inspeção sanitária.

\section{Material e métodos}

Após o exame post mortem de rotina (Brasil, 1997) em matadouros-frigoríficos sob Inspeção Federal, 220 amostras de fígados de bovinos com lesões císticas e nodulares, das quais 50 eram de Goiânia (GO) e 170 de Barretos (SP), foram colhidas, fixadas em solução de formol a $10 \%$ e enviadas ao Serviço de Anatomia Patológica Veterinária da Universidade Federal Fluminense, para processamento habitual de inclusão em parafina e coloração pela hematoxilina-eosina (HE).

\section{Resultados}

Foram observadas 41 ocorrências de macrófagos espumosos, sendo $27(15,88 \%)$ oriundas de Barretos (SP) e 14 (28\%) de Goiânia (GO). Microscopicamente, o infiltrado de macrófagos, de citoplasmas finamente vacuolares, levemente acidófilos e volumosos, com núcleos excêntricos e, freqüentemente, múltiplos, estava organizado em ninhos, em grandes massas subcapsulares ou formando grandes nódulos no parênquima (Figuras 1A, 1B e 1C). Em um caso notou-se colangiohepatite granulomatosa, rica em células gigantes multinucleadas, centralizada por cristais opticamente ativos (Figuras $D$ e $E$ ). Neste caso, houve, ainda, disposição difusa dos macrófagos
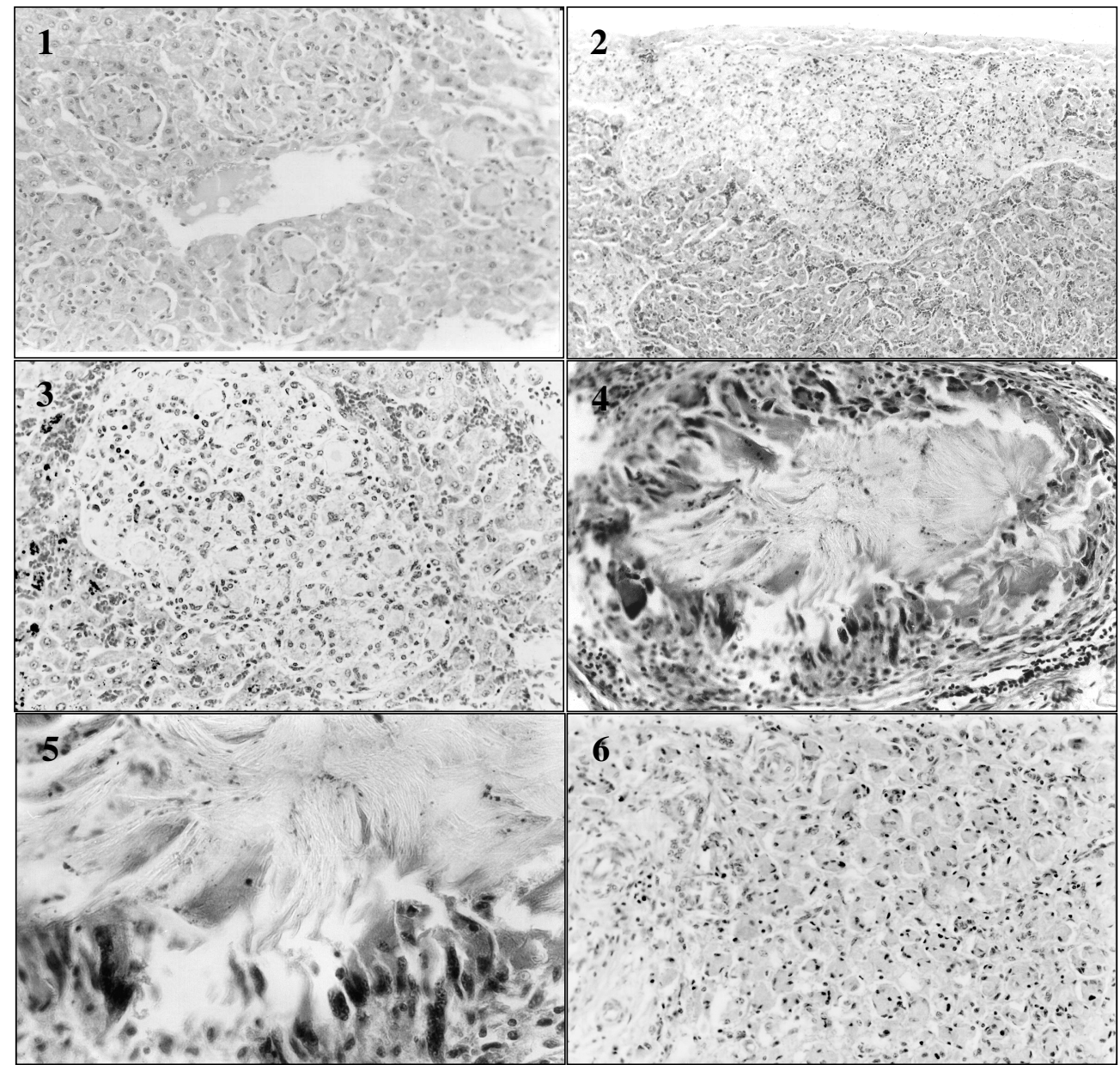

Figura 1: A- Bovino - Fígado - Ninhos de macrófagos, com citoplasmas finamente vacuolares, levemente acidófilos e volumosos, com núcleos excêntricos na periferia da veia centro-lobular. HE, obj. 20X. B- Bovino - Fígado - Extenso infiltrado subcapsular de macrófagos espumosos com núcleos múltiplos. HE, obj. 10X. C- Bovino - Fígado - Lesão nodular rica em macrófagos espumosos. HE, obj.20X. D- Bovino - Fígado - Colangite granulomatosa, rica em células gigantes multinucleadas, centralizada por cristais. HE, obj. 20X. E- Bovino - Fígado - Colangite granulomatosa. Detalhe das células gigantes multinucleadas e da disposição dos cristais centralizando o granuloma. HE, obj. 40X. F- Bovino - Fígado - Infiltrado difuso de macrófagos espumosos, ao lado de fibrose e hiperplasia de ductos biliares. HE, obj. 20X. 
que determinou a formação de ilhotas de hepatócitos, fibrose e hiperplasia de ductos biliares (Figura F).

Os fígados que apresentaram áreas de maior confluência dos macrófagos espumosos revelaram discretas áreas esbranquiçadas à inspeção, tendo a maioria apresentado coloração normal. Em nenhum dos casos houve registro de fotossensibilização.

\section{Discussão}

A fotossensibilização hepatógena nem sempre se manifesta clinicamente em animais alimentados com Brachiaria sp. Os estudos de Driemeier et al. (1998) e Cruz et al. (1999) ratificam essa assertiva. De fato, neste trabalho não houve relato de casos desta moléstia. Contudo, indivíduos clinicamente sadios podem apresentar lesões hepáticas, em linfonodos e até mesmo no baço.

As principais lesões são observadas no fígado, sendo, macroscopicamente, caracterizadas por alterações de tonalidade (Lemos et al., 1996a; Lemos et al., 1997; Driemeier et al., 1998; Cruz et al., 1999). No presente estudo, tais alterações não foram marcantes, uma vez que a maioria dos órgãos tinha a coloração normal, diferentemente das descrições literárias. Somente os fígados que apresentaram áreas de maior confluência de macrófagos espumosos revelaram áreas opacas, levemente esbranquiçadas, subcapsulares.

Driemeier et al. (1998) e Driemeier et al. (1999) também descreveram os macrófagos espumosos no fígado de bovinos, mas não observaram os cristais birrefringentes nos ductos biliares. Por conseguinte, Lemos et al. (1996a), Lemos et al. (1997b) e Cruz et al. (1999) fizeram menção às células espumosas e à colangiohepatite granulomatosa associada a cristais opticamente ativos nos ductos biliares. Apesar destes achados terem sido observados em um caso neste estudo, deve-se ressaltar a sua particularidade, tendo em vista que a disposição difusa dos macrófagos determinou a perda de arquitetura do órgão. A colangiohepatite granulomatosa,

\section{Referências}

ALESSI, A.C.; FAGLIARI, J.J.; OKUDA, H.T.; PASIPIERI, M. Intoxicação Natural de Bovinos pela Micotoxina Esporidesmina. 4. Lesões Hepáticas. Arq. Bras. Med. Zoot. v. 46, n. 4, p. 319-328, 1994.

BLAKISTON, P. Dicionário Médico Blakiston. 2. ed. São Paulo: Andrei, 1979. 1169 p.

BRASIL. Ministério da Agricultura. Lei 1283 de 18/12/1950, regulamentada pelo decreto 30691 de 20/03/1952 e alterado pelo Decreto 1255 de 25/06/1962. Regulamento de Inspeção Industrial e Sanitária de Produtos de Origem Animal. RIISPOA, 1997.

CRUZ, C.; COLODEL, E.M.; LORETTI, A.P.; GUTIERREZ, R.; SEITZ, A.L.; DRIEMEIER, D. Estudo Experimental das Lesões causadas por Brachiaria decumbens em Ovinos. ENCONTRO NACIONAL DE PATOLOGIA VETERINÁRIA, 9., Belo Horizonte, Minas Gerais. Anais... p. 135, 1999.

CRUZ, C.; DRIEMEIER, D.; PIRES, V.S.; COLODEL, E.M. et al. Isolation of Steroidal Sapogenins Implicated in Experimentally Induced Cholangiopathy of Sheep Grazing Brachiaria decumbens in Brazil. Vet Human Toxicol. v. 42, n. 3, p. 142-144, June, 2000. associada a cristais birrefringentes é referida, ainda, por Lemos et al. (1997a), Driemeier et al. (1997) e Cruz et al. (2000) que, no entanto, não fazem comentários sobre os macrófagos espumosos.

Enfim, as manifestações clínico-patológicas sobre o tema deste trabalho permitiram inferir que: os ruminantes podem desenvolver a fotossensibilização hepatógena (Smith e Miles, 1993; Meagher et al., 1996; Lemos et al., 1996a; Lemos et al., 1996b; Lemos et al., 1997a; Lemos et al., 1997b; Cruz et al., 1999) ou não (Driemeier et al., 1998; Cruz et al., 1999), quando mantidos em pastagens de Brachiaria sp. Tanto animais com fotossensibilidade como os clinicamente saudáveis, que ingeriram a forrageira em questão, podem apresentar lesões, principalmente em fígado, cujo exame microscópico revela hepatite representada por infiltrado de macrófagos espumosos característicos (Driemeier et al., 1998; Driemeier et al., 1999). Concomitantemente à observação desses elementos celulares pode haver colangite granulomatosa, associada a cristais birrefringentes nos ductos biliares, bem como hiperplasia desses ductos e fibrose (Lemos et al., 1996 a; Lemos et al., 1997 b; Cruz et al., 1999).

Convém ressaltar que animais sem fotossensibilidade podem apresentar apenas as células espumosas (Driemeier et al., 1998) ou a colangite com os cristais opticamente ativos (Driemeier et al., 1997) ou ambos os achados microscópicos, conforme relatado nesta pesquisa. Animais com fotossensibilidade geralmente apresentam tais achados simultaneamente, porém Lemos et al. (1997a) não fazem citação aos macrófagos espumosos.

Pelo exposto, sugere-se que o fiscal agropecuário aplique os dispositivos cabíveis, estabelecidos no artigo 191, do Regulamento de Inspeção Industrial e Sanitária de Produtos de Origem Animal (Brasil, 1997), que preconiza a condenação de órgãos de coloração anormal, mesmo nos casos discretos, e associe as manifestações clínicas de fotossensibilização, observadas no exame ante mortem, com lesões hepáticas no exame post mortem.

DÖBEREINER, J.; TOKARNIA, C.H.; MONTEIRO, M.C.C.; CRUZ, L.C.H. et al. Intoxicação de Bovinos e Ovinos em Pastos de Brachiaria decumbens contaminados por Pithomyces chartarum. Pesq. Agropec. Bras., Sér. Vet. v. 11, p. 87-94, 1976. DRIEMEIER, D.; BARROS, S.S.; PEIXOTO, P.V.;TOKARNIA, C.H.; et al. Estudos Histológico, Histoquímico e Ultra-Estrutural de Fígados e Linfonodos de Bovinos com presença de Macrófagos Espumosos ("foam cells"). Pesq. Vet. Bras. v. 18, n. 1, p. 29-34, jan./mar. 1998.

DRIEMEIER, D.; DÖBEREINER, J.; PEIXOTO, P.V.; BRITO, M.F. Relação entre Macrófagos Espumosos ("foam cells") no Fígado de Bovinos e Ingestão de Brachiaria spp no Brasil. Pesq. Vet. Bras., v. 19, n. 2, p. 79-83, abr./jun. 1999.

DRIEMEIER, D.; KREIMEIER, R.D.; COLODEL, E.M.; FRIES, C.; SEITZ, A.L.; SCHMITT, A.C. Colangiopatia Experimental Induzida por Alimentação de Ovinos com Brachiaria decumbens. ENCONTRO NACIONAL DE PATOLOGIA VETERINÁRIA, 8., 2125 julho, Pirassununga, S. P. (PE-16), 1997.

FAGLIARI, J.J.; OLIVEIRA, J.A.; PASSIPIERI, M. Sintomas de Fotossensibilidade em Bezerros Alimentados com Leite Materno. Arq. Bras. Med. Zoot., v. 35, n. 4, p. 479-484, 1983. 
FAGLIARI, J. J.; PASSIPIERI, M.; KUCHEMBUCK, M. R. G; CURI, P. R. Intoxicação Natural de Bovinos pela Micotoxina Esporidesmina. II. Aspectos clínicos. Arq. Bras. Med. Zoot., v. 45, n. 3, p. 275-282, 1993.

LAJIS, N. H.; ABDULLAH, A. S. H.; SALIM, S. J. S.; BREMNER, J. B.; KHAN, M. N. Epi- Sarsasapogenin and epi-Smilagenin: two saponins isolated from the rumen of sheep intoxicated by Brachiaria decumbens. Steroids. v. 58, p. 387-389, ago. 1993.

LEMOS, R.A.A.; FERREIRA, L.C.L.; SILVA, S.M.; NAKAZATO, L.; SALVADOR, S. C. Fotossensibilização e Colangiopatia Associada a Cristais em Ovinos em Pastagem com Brachiaria decumbens. Ciência Rural, Santa Maria, v. 26, n. 1, p. 109-113, 1996 a.

LEMOS, R.A.A.; NAKASATO, L.; SALVADOR, S.C. Alterações Histológicas no Fígado de Ruminantes com Fotossensibilização Hepatógena Associada a Ingestão de Brachiaria decumbens e Brachiaria brizantha. ENCONTRO NACIONAL DE PATOLOGIA VETERINÁRIA, 8., 21-25 julho, Pirassununga, S.P. (PA-59), 1997b.

LEMOS, R.A.A.;OSÓRIO.AL.A.R.;RANGEL, J.M.R.;HERREROJÚNIOR, G.O. Fotossensibilização e colangiopatia associada a cristais em bezerros ingerindo Brachiaria brizantha. Arq. Inst. Biol. São Paulo. v. 63 (supl.), p. 22, 1996 b.

LEMOS, R.A.A.; SALVADOR, S.C.; NAKASATO, L. Photosensitization and Crystal-Associated Cholangiopathy in Cattle Grazing Brachiaria decumbens in Brazil. Vet Human Toxicol. v. 39, n. 6, p. 376-377, December, $1997 a$.
MEAGHER, L.P.; WILKINS, A.L.; MILES, C.O; COLLIN, R.G.; FAGLIARI, J.J. Hepatogenous photosensitization of ruminants by Brachiaria decumbens and Panicum dichotomiflorum in the absence of sporidesmin: lithogenic saponins may be responsible. Vet. Hum. Toxicol. v. 38, n. 4, p. 271-274, ago. 1996.

MILES, C.O. A role for esteroidal saponins in hepatogenous photosensitisation. New Zealand Veterinary Journal. p. 121, 1993.

NOORDIN, M.M.; SALAM, A; RAJION, M.A. Experimental Brachiaria decumbens toxicity in cattle. Veterinary Research Communications, v. 13, n. 6, p. 491-494, 1989.

SALAM ABDULLAH, A.; LAJIS, N.H.; BREMNER, J.B.; DAVIES, N.W.; MUSTAPHA, W.; RAJION, M.A. Hepatotoxic constituents in the rumen of Brachiaria decumbens intoxicated sheep. Vet. Hum. Toxicol. v. 34, n. 2, p. 154-155, abr., 1992.

SMITH, B.L.; MILES, C.O. A letter to the editor. A role for Brachiaria decumbens in hepatogenous photosensitization of ruminants?. Vet. Hum. Toxicol. v. 35, n. 3, p. 256-257, jun. 1993.

TEMPERINI, J.A.; BARROS, M.A. Revisão sobre Aspectos Químicos e Físicos Ligados ao Fenômeno de Fotossensibilização e Efeitos Biológicos da Esporodsmina Obtida do Fungo Pithomyces chartarum (Berk e Curt) M.B. ELLIS. O Biológico, v. 3, p. 103-110, 1997. 